\title{
Prospects of value-added poultry products marketing in India
}

\author{
Thyagarajan Desikan ${ }^{1}$, Barathi Megarajan ${ }^{2}$ \\ ${ }^{1}$ Distance Education, Tamilnadu Veterinary and Animal Sciences University, Chennai, India \\ ${ }^{2}$ SRF, Directorate of Distance Education, Tamilnadu Veterinary and Animal Sciences University, Chennai, India
}

Email address:

drthyagu2002@yahoo.com (D. Thyagarajan), barathimegarajan@gmail.com (M. Barathi)

\section{To cite this article:}

Thyagarajan Desikan, Barathi Megarajan. Prospects of Value-Added Poultry Products Marketing in India. Animal and Veterinary Sciences. Vol. 2, No. 4, 2014, pp. 118-123. doi: 10.11648/j.avs.20140204.16

\begin{abstract}
Poultry industry in India is making major forward changes in productivity enhancement, industry expansion, research and development changes and marketing network. As to the extent of farming sector growth, concurrent expansion of the processing and further processing is limited. Lack of expansion in processing due to low demand for processed foods leads to restriction in the production of quality products. Poultry industry having $8 \%$ and $12 \%$ growth rate in broiler and layer industry needs to plan for quality production of poultry meat products and by-products and also in egg products and egg by-products. Further sustainability and profitability of the industry depends upon the diversification. Need based technology for meat products like emulsion, sausage, restructured, cured, enrobed, retort-packed, heritage products and value- addition to edible by-products are well established. Likewise postharvest technology for pickled egg, salted chicken egg, albumin rings, egg roll, egg crepe and egg powder are also available. Added to the well planned growth of the industry, defined and refined technologies are available as a major strength for numerous value-added meat products, egg products and by-products. Further limited diversification of poultry products industry is attributed to lack of adequate infrastructure facilities for processing and storage. Expansion of marketing is possible with major policy support, creation of facilities and reaching the consumers with quality and safety products. Disturbances in poultry marketing network are mainly reasoned out for monopoly of traders and restricted profit to the consumers. Overall poultry products marketing mainly depends on organized marketing network, creation of processing infrastructure facilities, quality and safety compliance in food chain from production to consumption.
\end{abstract}

Keywords: Poultry Meat, Value-Added Meat Products, Egg Products, Poultry Marketing, Marketing Advantages

\section{Introduction}

Poultry industry in India is a mega billion industry having third position in egg production and fifth position in broilers in the world. The total egg production accounts to 68 billion and broilers 2.8 billion. The average cumulative growth rate in layer and broiler is $8 \%$ and $12 \%$ respectively. Even though production is in accelerated trend still processing and marketing strategies are not in a well defined manner which leads to overall moderate profitability and less export promotion. This sector is responsible for $0.45 \%$ of India's Gross Domestic Product (GDP) and $10 \%$ of livestock GDP. Poultry production in India contributes to $5 \%$ of meat and $2.5 \%$ egg of total global output. Even though production is in faster rate, the per capita consumption of egg and poultry meat is 52 eggs and $2.4 \mathrm{Kg}$ of meat. In India the consumption pattern varies between urban and rural areas. In urban areas one third of the population consumes two third of the poultry products due to increased farm size, increased income and better knowledge on health and nutritional benefits of poultry meat. But in rural areas due to decreased knowledge on nutritional benefits of poultry meat and poor families their consumption is lower than urban people (Hai et al. 2008)

Irrespective of massive breakthrough in production front, the processing sector is still in infantile stage and marketing sector is mostly in disorganized way (Singh 2012)Currently only $20 \%$ of the chicken and $6 \%$ of the eggs are processed. Among the dressed chickens, $70 \%$ are sold as dressed or chilled or frozen whole carcass, limiting remaining $30 \%$ to cut up parts and further processed products. On the other hand, in the industrialized countries, whole broiler sales 
recorded at $15 \%$, cuts and boneless breast fillets 35\%, further processed products $50 \%$. Likewise $30 \%$ of the eggs produced are processed as pasteurized chilled-frozen liquid egg, dehydrated and ready to eat egg products. Right now, only dozen modern mechanized processing plants with capacity of 2000-4000 chicken per hour and three export oriented egg processing plants process the 4.5 million eggs per day (Singh 2012).

Major constraints in our country for lack of processing is less preference for frozen chicken by the consumer, insufficient cold chain infrastructure facilities, lack of well organized marketing system, less domestic demand for value-added egg products, non-availability of adequate technology, fluctuating export trade, high import duty and strict sanitary and phytosanitory norms by importing countries. However, India with so many limitations now emerged as a leading exporter of shell eggs, frozen and dehydrated egg products and frozen broilers accounting to Rs.458 crores during 2011-12. Indian poultry Industrial growth is accelerated by gains in real per capita income and changes in poultry prices. This review discusses in brief about the current trend in poultry processing industries, present market scenario and the strength and weakness of Indian poultry marketing system.

\section{Commercial Poultry Meat Products}

Chicken meat products prepared from ground meat are emulsion based technologies which have the advantages of improved palatability, nutritive value and lesser production cost. Application of processing technology depends on global competitiveness, energy conservation and socioeconomic benefits.

\subsection{Emulsion Products}

Emulsion products like chicken meat blocks, nuggets, slices and patties utilizes tough meat, trimmings and edible by-products. The common steps of processing include comminuting/mincing to reduce meat and fat particle size (grinding, mincing, chopping or flaking), mixing with ingredients, making into specific shape, thermal processing and finally packaging.

Chicken nuggets are produced by making the meat batter into blocks and cutting the steam cooked and chilled meats into nuggets of different slices. Burgers/patties which contain $70 \%$ meat are prepared by mincing the meat, blending with ingredients, forming batter into patties which are cooked at $180^{\circ} \mathrm{C}$ (Anjaneyalu et al. 2012).

\subsection{Processing of Sausages}

Sausages are made by cutting meat and fat into fine pieces mixed with spices and stuffed into animal intestines and cooked in hot water. Emulsion based sausages are made by grinding, chopping, stuffing, linking, cooking, peeling, slicing and packaging. They are categorized by United States Department of Agriculture (USDA) meat inspection system as fresh, uncooked smoked, cooked, smoked, dry and semidry sausages and luncheon meat, loaves and jellied products (Anjaneyalu et al. 2012).

\subsection{Restructured/Low Fat Chicken Products}

These are meat products having high protein and low fat made by restructuring dark and white meat from heavy broilers. Excessive fat is trimmed off and other connective tissues are chunked out and formed. Blade tenderization, flaking and bay tumbling are modern methods available to produce tender products. Prepared meats can be used as steaks, cutlets, chops and roasts or they can be freezing stored (Anjaneyalu et al. 2012).

\subsection{Cured and Smoked Products}

Curing process involves addition of curing agents like salt, sugar, sodium nitrite, sodium ascorbate and sodium polyphosphate to the primal chicken cuts for enhancement of colour, flavour and preservation. Chicken is injected with pickle and dipped in it for faster curing giving a juicy texture. Smoking involves heating, drying, smoking, steaming/ cooking showering, chilling and packaging which give a distinctive flavour. Cured and smoked chicken on the whole has a niche market (Anjaneyalu et al. 2012).

\subsection{Enrobed/Coated Products}

Enrobing involves applying an edible coating to the products forimproving their texture, flavour, nutritive value, juiciness and tenderness. They act as sealing agents to prevent excess oil absorption. Chicken parts can be enrobed using whole egg liquid (viscous liquid and good batter), curd, flours, corn flakes and bread crumbs which give crispy taste (Anjaneyalu et al. 2012).

\subsection{Retort Pouched Products}

Thermal processing of meat destroys microorganisms and enzymes responsible for food spoilage. Thermal processing in metal cans or retort pouches increases shelf life of products and decreases $50 \%$ processing time. Some products include traditional Indian curries, soups, Keemas etc. Retort packaged products could be stored for a period of 6 to 12 months (Anjaneyalu et al. 2012).

\subsection{Heritage Products}

Heritage chicken products include traditional fast foods such as meat balls, kebabs, tikka, chicken tandoori, haleem, curries, enrobed and battered products and pickles which are prepared from chicken breast, thigh, drumstick and gizzard muscles. Pickles preserved with vinegar are stable up to 3 months (Anjaneyalu et al. 2012).

\subsection{Value Addition to Edible by Products}

Edible poultry by products like dressed whole chicken carcass and giblets such as liver, heart, gizzard and neck have good marketing values which are sold as package 
stuffed into cavity of carcass. Minced skin, gizzard and heart are used in emulsion of chicken products. Ova collected during dressing of layer chickens are used in sausage formulations, patties and kebabs. Chicken soup is another nutritious food that is categorized as low fat food (Anjaneyalu et al. 2012).

\section{Commercial Egg Products}

Egg products at USDA may be classified under following ways

(a) Refrigerated (as liquid) e.g. Whole eggs, whites or yolks, sugared egg yolks, salted egg yolk, scrambled egg mix, extended shelf life whole eggs

(b) Frozen: e.g. Whole egg, white or yolk, scrambled egg mix, salted whole egg, sugared egg yolk and whole egg mix

(c) Dried: e.g. White egg or yolk solids, dried egg, whole egg

(d) Specialty products: e.g. dried hard cooked, peeled egg, whole hard cooked peeled egg, egg yolk, long egg quiche mix, and ultra-pasteurized liquid egg products.

Certain commercialized egg product preparations are as follows

1. Pickled eggs: A simple, cost-effective and efficient technology developed for ready to eat pickling of quail eggs/ chicken eggs for storage and marketing at ambient temperature.

2. Salted chicken eggs: Preparation of salted chicken eggs technology is so simple to be used by unskilled people.

3. Albumen rings: Albumen rings are egg snack food, prepared by cooking blended egg albumen in ring moulds and battering and breading the coagulated albumen prior to deep fat frying.

4. Egg roll: It is a nutritious, tasty and convenience egg product suitable for meals or as snack foods.

5. Egg crepe: Egg crepe is a thin, fat, circular product and may be filled with meat or vegetables and rolled or folded.

\section{Advantage of Poultry Products Marketing}

Encouraging the poultry product marketing ensures steady flow of products to the consumer in an effective manner, thereby increasing the economic activity. It further maintains the steady price distribution for the sale of product in much profitable manner due to high returns. It also gives way to employment generation and income generation activity. Marketing of the poultry product can also enhance the nutritional security of the different target groups. Marketing of the poultry products make the poultry products available at the right time, right place in right quantity and at right price. However in India major problem in marketing is the lack of efficient and organized market network.

\subsection{Production Cost}

In general the average variable cost of production is lowest in the south followed by west, east and north. The feed consumption rate (FCR) based market is generally higher in the north because of higher market weight, higher mortality rate due to extremes of hot and cold temperature. Projected global egg and meat production during 2020 are 77 million tons and 123 million tons to cater to the demands of 8 million of the human population.

\subsection{Channels of marketing}

Currently more than $75 \%$ of the poultry products are reaching the consumers through various channels of distribution leading the consumers to pay more and producers to get fewer margins. Besides, major share of the profit at present goes to the middlemen. At present poultry products are marketed in the following four marketing networks.

1. Producer-Consumer

2. Producer- Wholesaler- Retailer- Consumer

3. Producer- Collector- Assembly merchant- Consumer

4. Producer- Retailer

Channel 2 may account to marketing of major portion of eggs to the consumers. Channel 4 is responsible for getting $12-15 \%$ of the total profit to the retailers. However in channel 2 a middleman gets $22 \%$ of the profit. National Egg Coordination Committee owned by private sector organization and National Agricultural Cooperative Marketing Federation governed by Government of India to some extent streamline the marketing of major poultry products.

Major Meat consumption pattern in India are towards fish, mutton, bovine and goat meat as given in the figure 1 below:

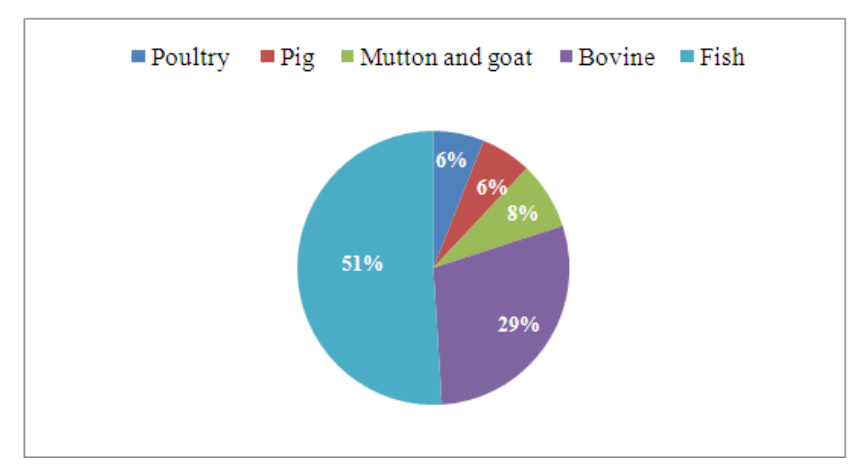

Fig 1. Meat consumption pattern in India.

\subsection{Prospects of Poultry Marketing}

Considering the fast growth of the poultry industry in the past further growth and marketing of the poultry industry are limited due to the following factors

- Demand for poultry meat is highly price sensitive among low and middle income groups 
- Major limitation is logistics and distribution network within India mostly due to limited demands for frozen products, high cost of transport infrastructure, unreliable cold chain facilities and the quality of the products produced.

- Vertical integration encourages higher production, better marketing efficiency with reduced consumer prices

- In India marketing efficiency is important than the production efficiency

- $\quad$ Competitive feed price results in competitive meat and egg production

- Seasonal variation due to religious practices

\subsection{Foreign Direct Investment (FDI)}

Foreign direct investment is yet to take a forward movement in India's poultry sector. However, FDI has the potential to invest in important input activities like breeding, medicine, feed, equipment, vertical integration and processing. Still major limitation for the FDI in India is due to unstable market, poor power, transport facilities and high taxes on processed food. Expansion of the poultry industry marketing mainly depends on the transition from live bird market to a chilled or frozen product model. Live bird market restricts the exploitation of the regional imbalance, use of storage facilities for domestic product movement and export promotion to stabilize the demand and supply. In addition, movement of live birds increases the cost of production due to transport, shrinkage and mortality. Altogether Indian poultry market is regional rather than national limiting low cost producer to market the products in higher cost region. Preference for the live bird is mostly due to reliability on the quality of the fresh poultry meat that is slaughtered in their presence. Foreign direct investment is now most common in the pharmaceuticals as most of the companies in India are multi-national corporations. In respect of feed production, most of them are India feed companies except Java Pelletizing Factory Comfeed India Pvt. Itd. (JAPFA) from Indonesia and Charoen Pokphand (CP) from Thailand.

Major advantage for trading in India by FDI is attributed to thirty percent local outsources from small and medium size industries, backward infrastructures investment to strengthen the supply chain and other obligations. Consequent to entry of Foreign Direct Investment (FDI), there will be following three major changes.

1. Investment by multinational retailers in start of art of technology

2. Participation of more international trade

3. Possibilities of larger portion of market by Multinational Corporation (MNC) due to monopsony.

\subsection{Private Players in Poultry Industry}

The major private industries involved in the poultry processing, further processing operations and marketing poultry products are Venkateshwara Hatcheries Pvt. ltd., ,
Suguna Poultry farm ltd., CP (Charoen Pokphand India), KFC (Kentucky Fried Chicken), SRM agro foods, McDonald's and Arthur's food company pvt. ltd.

\subsection{Prospects of Future Poultry Products Marketing}

\subsubsection{Strength: Technology Identified}

\subsubsection{Chicken Meat}

Continuous research and development efforts lead to generation of cost-effective and efficient technologies for the processing and preservation of egg and poultry meat, tenderization of spent hen meat, deduction of meat adulteration, development of value added poultry products, packaging systems, optimum storage conditions, utilization of poultry by-products etc. Besides, thorough inbuilt measures are established to detect hazardous residues like pesticides, antibiotics, antibacterial, heavy metals, mycotoxins and biopathogens.

Currently some of the processing techniques include hot/cold deboning, thermal hydrolysis, enzymatic and blade tenderization of tough meat, massaging and tumbling for increasing myofibrillar proteins solubility and meat particle binding, flaking and dicing for restructured products, chopping and emulsification for comminuted products, marinating/ battering and breading for enrobed products, canning, curing and smoking and hurdle technology for shelf-stable poultry products.

Some of the value added poultry products include chicken essence, chicken whey soup mixes, tandoori, barbecues, canned/retort processed chicken products in flexible pouches, cured and smoked chicken, chicken meat and skin snacks, gizzard snacks, cooked chicken stock, enrobed thighs, drumsticks and wings, marinated chicken breast fillets, chicken spread, shelf- stable spiced chicken bits, wafers, freeze- dried chicken pulav, retort- processed curried chicken, and intermediate moisture chicken meat etc. Other restructured products like chicken sausages, patties/ burgers, nuggets, rolls, loaves, balls, cutlets, steaks, kebabs, croquettes and chunkalona are other quality products developed from low value spent hen or culled breeder meat, skin, gizzard, heart, ova yolk and adipose fat.

\subsubsection{Egg}

Almost two-thirds of the global egg production has occurred in developing regions of Asia. Egg processing is mainly dominated by industrialized countries where $35 \%$ of table eggs are converted into processed products. Table eggs and liquid egg products are traded within European and Asian countries. Dehydrated egg products are better traded in large amounts because of its long shelf- life and low transport cost.

India has also ventured in this on a modest scale. India's combined egg processing plants capacity is at 12000 metric tons per year. Major areas of research in egg processing in India is on design and fabrication of a low cost, batch -type immersion egg washing machine and development of egg washing powder. Recent advancements in egg processing 
technology include improved egg spray washers and egg coating oil for preservation which maintains the quality of eggs up to 4 weeks at ambient temperature $\left(26^{\circ} \mathrm{C}\right)$. Further processes have been developed to control gelatin in frozen yolk/whole egg liquid by $0.02 \%$ pepsin, $0.5 \%$ trypsin, 5 to $10 \%$ common salt or cane sugar or $5 \%$ glycerol in the egg magma prior to freezing.

Manufacturing technologies for a number of valueadded products live as whole egg powder, yolk granules, albumen flakes, albumen rings waffles, canned curried eggs, scrambled egg, omelet premixes, egg patties, egg- chicken meat patties, egg pizzas, egg roll, sponge and pancakes, albumen yolk cubes, mayonnaise, egg- enriched biscuits, breads and egg milk beverages have been adopted.

Ultra-pasteurization-cum-aseptic packaging techniques are also available to extend the refrigerated shelf-life of liquid egg up to 4 and 24 weeks at $10^{\circ} \mathrm{C}$ and $4^{\circ} \mathrm{C}$ respectively for marketing in non-frozen form. Presently another advanced method of vacuum evaporation of liquid whole egg followed by quick freezing to produce frozen egg pellets has also been developed.

\subsubsection{By-Products}

Poultry slaughter waste, hatchery waste and egg shell waste are being generated to the tune of three lakh tons, 0.6 lakh tons and 0.34 lakh tons respectively in India. Conventional methods are being employed to convert the egg shell into egg shell meal by centrifugation to recover residual albumin subsequently with autoclaving, oven drying and grinding into coarse or fine powder. Extrusion technology has also been attempted to utilize the poultry by-products into extruded pet food. Unorganized disposal of poultry offal could be easily transported using $2 \%$ formic acid or $4 \%$ acetic acid for the period of 10 days at $26 \pm 2{ }^{\circ} \mathrm{C}$. Projected global egg production and meat production during 2020 are 77 million tons and 123 million.

\subsubsection{Weakness}

\subsubsection{Need for Emerging Technologies to Encourage Marketing}

Marketing of any products depend upon its shelf life, maintenance of nutrient content, easy transport, ecofriendly packing material, easy availability, aesthetic acceptance of the consumers. Accordingly there is a necessity to concentrate on the research and development wing to come out with newer technologies on the following lines.

- Design of mini poultry processing units

- Shelf-life extension of poultry products by application of hurdle technology and biotechnology means

- Developing newer techniques for tenderization of meats

- Efficient processing techniques for extraction of lysozyme, avidin, lecithin and other biomolecules from eggs

- Ultra-pasteurization cum aseptic packaging technology for liquid egg
- Uniform processing technology for traditional poultry products

- Improved packaging techniques like vacuum, MAB, CAP, retort and aseptic

- Development of quick and sensitive methods for detection of pathogens and hazardous feed residues

- Application of bio- processing techniques for efficient disposal of poultry products

- User-friendly transport system as per the food engineering norms

\subsubsection{Opportunities}

Rapid urbanization, industrialization, rising disposable income, changing food habits towards processed products and higher middle income group are major positive factors to boost up processed food markets. Strict adaptation of GMP and HACCP system can give major possible export of frozen broilers in the European Union, Japan and Russia as per Rabo bank report 2008. Major limitation factor for export of poultry products is attributed to non-compliance of quality norms prescribed by the codex alimentarius. Following are the major elements need to be given due attention to encourage the export of poultry products

- Application of modern processing techniques

- Provision of logistic support

- Production of quality products fit for export

- Policy changes in the government level

- Developing the appropriate packaging technology

- Effective R \& D work to increase the shelf life of the products

- Harmonization of quality control norms

- $\quad$ Single window approach for export

- Creation of database

- Well trained techno graphs and skilled human resources

- NABL accredited laboratories for certification of food products

- Cost effective mini poultry processing units

\subsubsection{Threats}

\subsubsection{Marketing System}

At present poultry marketing is dictated by the private traders and commission agents present in various cities and towns. Most of the trading activity of the poultry meat and egg is in the disadvantageous position to the farmers giving lesser margins of profit than the traders' profit margin. Right now, organized marketing network need to encourage positive trend for uniform profits to all the players in the poultry industry.

\section{Conclusion}

Indian Poultry Industry is one of the fast growing markets in poultry production accounting to 2.8 billion broiler and 68 billion egg production. Although poultry industry shows enormous growth, the poultry processing sector is still underdeveloped due to less demand for the 
ready to eat and cook products and less acceptability of processed poultry products. At present marketing of poultry products has many hurdles such as, unstable market, increased taxes on processed foods, competitive feed costs, high transportation charges, lack of cold chain facilities and non-compliance of food safety norms. However continuous research and development leads to the development of low cost and efficient poultry processing technologies and well established quality control norms. Poultry marketing system in India dominated by private traders and commission agents needs to be transformed into an organized system for uniform sharing of profits by all players in the industry.

\section{References}

[1] Hai, M.A., M.Mahiuddin, M.A.R. Haulider and T. Yeasmin, 2008. Pattern and problem of poultry consumption by the rural and urban families of Fulbaria Upazila, J. Bangladesh Agril. Univ. 6(2): 307-313.

[2] USDA. Agriculture and trade reports: India's Poultry sectorDevelopment and prospects.

[3] Anjaneyalu, A.S.R., M.Muthukumar and I.PrinceDevadason, 2012. Processing technologies of value added chicken products for employment generation, IPSACON, pg. 116121.

[4] Singh, R.P., 2012. Present status and prospects of egg and poultry processing in India, IPSACON, pg. 111-115.

[5] USDA: FSIS Egg Products Training Student Manual Module III. 